\title{
Preference for familiar humans by rats
}

\author{
HANK DAVIS, ALLISON A. TAYLOR, and CHRISTINA NORRIS \\ University of Guelph, Guelph, Ontario, Canada
}

\begin{abstract}
Many "higher" animals are commonly assumed to distinguish between individual humans. This belief is based largely on anecdotal reports; in reality, there is little empirical evidence to support human recognition in nonhuman species. We report that laboratory rats consistently chose a familiar human over an unfamiliar human following fourteen and five 10-min exposures and even following a single 10-min exposure. Furthermore, this preference was retained in the absence of additional contact for at least 5 months. These results confirm that laboratory rats can tell individual humans apart, a prerequisite for associating them with hedonic events. Such human-based conditioning, described by Pavlov and by Gantt, Newton, Royer, and Stephens (1966), may have important implications for animal research in a variety of settings.
\end{abstract}

Can the ubiquitous laboratory rat recognize individual humans? There is evidence that, like many animals, rats can discriminate individuals within their own species (Halpin, 1980; Hopp, Owren, \& Marion, 1985; Randall, 1989). Indeed, Thor and Holloway (1982) describe rats as "normally engaging in spontaneous learning of individual identity" (p. 1000). But can such individuals be of another species, and, more specifically, can they be human?

The recognition by animals of individual humans is not without precedent. For example, there is evidence that dogs (Settle, Sommerville, McCormick, \& Broom, 1994), sheep (Fell \& Shutt, 1989), pigs (Tanida, Miura, Tanaka, \& Yoshimoto, 1995), and prairie dogs (Slobodchikoff, Kiriazis, Fischer, \& Creef, 1991) can tell humans apart. However, there is as yet no comparable evidence that rats can distinguish individual people.

Whether rats can discriminate between humans may have implications beyond the study of animal cognition. If research animals, such as rats, can differentiate one human from another, and this human is repeatedly paired with significant hedonic events in the animal's life, Pavlovian conditioning is likely to occur. Most research entails the delivery of hedonic stimuli, either through daily care or experimental manipulation. Gantt, Newton, Royer, and Stephens (1966) recognized this human-based conditioning process and described it in terms of "person as CS." Davis and Balfour (1992) surveyed evidence that such an associative process may have motivational effects that raise methodological concerns for animal-based research.

This research was supported in part by Grant A0673 to the first author from the Natural Sciences and Engineering Research Council of Canada. All animals were cared for in accordance with the University of Guelph Animal Care Policy and Canadian Council on Animal Care guidelines. A portion of these data was reported at 1994 meetings of the Animal Behavior Society and the Psychonomic Society. The authors wish to thank Lill Svendsen and Susan Boehnke for their technical assistance. Correspondence should be addressed to H. Davis, Department of Psychology, University of Guelph, ON, Canada N1G 2WI (e-mail: hdavis@uoguelph.ca).
Although it is not our goal to identify the specific sensory basis of human recognition, knowing whether rats can discriminate individual humans is fundamental to assessing the likelihood of human-based conditioning in a research setting. The following experiments explore whether laboratory rats have a preference for a familiar human with whom they have had fourteen 10-min exposures, five 10-min exposures, or even a single 10-min exposure.

\section{EXPERIMENT 1}

In Experiment 1, rats were given 14 "bonding" sessions with one of two human handlers. Following this exposure, the animals were individually tested to determine whether they preferred contact with the familiar handler or a stranger.

\section{Method}

Subjects. Twenty-six female Long-Evans rats served as subjects. These animals were previously used in an undergraduate teaching laboratory and had been handled daily by their assigned students. All animals were housed in pairs, with food and water freely available throughout the experiment.

Procedure. The 26 subjects were equally divided between two female human handlers. Each animal spent fourteen 10-min sessions with one of the handlers. For each daily bonding session, the animal was removed from its home cage and carried to an experimental room, where it was petted, fed treats (shelled sunflower seeds), and allowed to climb on the handler's body. Handlers maintained a constant personal hygiene routine and did not change products (e.g., soap, deodorant) throughout the experiment.

On the 15th day, the rats were brought into a novel test room in random sequence by a third person who had no prior contact with any of the animals. The two handlers sat at opposite ends of a $45 \times 182 \mathrm{~cm}$ Melamine table, with forearms crossed on, and upper body perpendicular to, the tabletop. Handlers stared at a fixed point approximately $0.6 \mathrm{~m}$ above the tabletop. Neither handler knew whether the animal on any particular trial was "hers." The animals were placed individually at the midpoint of the table, facing in a direction perpendicular to the two handlers. The table surface was washed with water after each animal was tested. Sessions were videotaped and scored by two independent observers. Interobserver agreement exceeded $95 \%$.

Each animal was run for a single test session. The subjects were allowed a maximum of $10 \mathrm{~min}$ to select one of the two handlers. A choice was recorded only if the subject climbed with all four feet onto the han- 
dler's body and remained there for a minimum of $20 \mathrm{sec}$. At this point the trial was terminated.

Although the criterion for a choice is fairly strict, pilot tests revealed the importance of requiring the animal to use all four feet. The animals were thus allowed to engage in normal olfactory exploration, during which front paws were often tentatively rested on the handlers' forearm. Maintaining one or both rear paws on the table permitted the subjects to retreat rapidly without registering a choice.

\section{Results}

After intermittently sniffing both handlers, the subjects typically backed away from the "stranger," crossed the table, and climbed directly onto the familiar person. Twenty-four of 26 subjects selected the person with whom they had bonded (binomial $p<.00001$ ). Trials occasionally ended with the animal sitting on the familiar person's shoulder.

\section{EXPERIMENT 2}

To what extent can the rats' recognition of the familiar handler be retained? There is relatively little evidence for long-term retention of learning in rats. With few exceptions, early studies reviewed by Munn (1950) involve simple tasks (e.g., conditioned fear responses) and intertest intervals ranging from several hours to weeks. More recent studies, including those involving discrimination learning, continue to involve relatively brief retention intervals (e.g., Calhoun \& Handley, 1973; Henderson, 1978; Steinert, Infurna, \& Spear, 1980), although there is evidence of rats retaining associative learning for periods as long as 12 or 18 months (Davis \& Bradford, 1986). To determine whether the preference for a familiar handler could be retained for an extended period of time, the subjects from Experiment 1 were retested following a 5-month period.

\section{Method}

Subjects. The 11 surviving animals from the subject pool of Experiment 1 were retested. The subjects were housed and maintained as in Experiment 1.

Procedure. Following testing in Experiment 1, all animals were returned to their home cages for 5 months with no further exposure to either handler. Food and water were freely available throughout this period. The rats were tested using the original handlers from Experiment 1 . The test protocol and choice criteria were identical to those used in Experiment 1.

\section{Results}

Ten of 11 subjects chose the human with whom they had interacted 5 months earlier (binomial $p<.005$ ).

\section{EXPERIMENT 3}

To determine whether the results of Experiment 1 could be achieved with fewer human-animal interactions, a second group of animals was trained using only five brief "bonding" sessions.

\footnotetext{
Method

Subjects. Eight female Long-Evans rats similar to those used in Experiment 1 served as subjects. Four of these animals were expermmen-
}

tally naive, and 4 had been previously used in undergraduate teaching laboratories, as in Experiment 1. The animals were housed and maintained as in Experiment 1.

Procedure. The procedure was identical to Experiment 1, with three exceptions: (1) food was not provided during the 10-min bonding sessions, (2) different handlers were used, and (3) handlers were blindfolded during testing.

\section{Results}

Despite the reduction in the number of bonding sessions, all 8 subjects selected the familiar handler during testing (binomial $p<.005$ ).

\section{EXPERIMENT 4}

Experiment 4 examined whether a single bonding session in the absence of any food reward was sufficient to create the previously observed preference for the familiar human.

\section{Method}

Subjects. Fourteen Long-Evans rats ( 5 male, 9 female) served as subjects. Six animals had been previously used in undergraduate teaching laboratories, as in Experiment 1. The remaining 8 animals were experimentally naive. The subjects were housed and maintained as in the previous experiments.

Procedure. The subjects were given a single 10-min bonding session, identical to those in Experiment 3. Handlers different from those in Experiments 1-3 were blindfolded during testing. The animals were given a maximum of $15 \mathrm{~min}$ to choose one of the two handlers.

\section{Results}

Despite the fact that most animals continued to show overt signs of fear of the handler during the single 10min "bonding" session (e.g., startle responses, frequent urination and defecation), 13 of 14 animals selected the familiar human during testing $(p<.00001)$.

\section{DISCUSSION}

Collectively, the results of Experiments 1-4 demonstrate that rats can form preferences for individual humans on the basis of relatively minimal contact. Although the sensory mechanism underlying this behavior was not investigated directly, what is known of rodent physiology (Barnett, 1963), and observations of subjects' behavior during testing suggest that olfaction played a major role in performance. The present demonstration of discrimination between humans is consistent with reports that rats readily discriminate between individuals of their own species (e.g., Randall, 1989; Thor \& Holloway, 1982), presumably by olfactory means.

On the basis of our data, this ability appears to be independent of the rats' prior handling background (both experimental and naive animals were tested) and the individual humans involved. Moreover, this preference may be retained, without additional exposure, for periods of at least 5 months.

Furthermore, the results of Experiments 3 and 4 confirm that rats' preference for familiar humans does not depend on food delivery during bonding. It is not clear, however, whether human-based socialization is essentially positive, as the findings of Davis and Perusse (1988) suggest, or whether such contact serves to habituate neophobia. Although it is difficult to label the present experience in terms of conventional laboratory procedures, we believe the human contact offered in Experiments 1, 3, and 4 allows for the formation of an association between a particular human CS and positive hedonic events. In Pavlovian terms, our test procedure demonstrates a skeletal-motor approach CR directed toward the human $\mathrm{CS}$. There is precedent for the conditioning of social 
behavior in rats to conspecifics paired with food (Timberlake \& Grant, 1975). Viewed in these terms, our experiments have extended this demonstration from conspecific to individual human CSs, consistent with Gantt et al.ss (1966) model of "person as CS."

It is worth noting that the rats in our experiments were never trained to discriminate between humans. Although their reliable preference for a familiar person certainly reflects this ability, such discrimination emerged as a form of incidental learning. As Thor and Holloway (1982) have pointed out, "learning of individual identity" in rats, whether of conspecifics or humans, may be spontaneous and highly likely. The present experiments were unique because they allowed rats to express these individual preferences, which might otherwise have remained embedded in alternative dependent measures.

What impact might these preferences, or the discriminations they reflect, have on animal-based research? It is true that the CS-directed approach responses tested in our experiments are unlikely to interfere with most well-designed behavioral or biomedical research. These CRs do, however, confirm that rats do not simply generalize across all humans thus, individual persons may enter into associative relationships with the hedonic stimuli that are a mainstay of research with animals. Even when CS-directed approach is precluded, a variety of anticipatory CRs may affect behavioral and physiological variables in measurable ways. For example, Summerlee (1992) has reported changes in rats' and rabbits' cortical arousal specifically tied to the familiarity of the human handler Unfamiliar handlers, such as those used as "occasional labor" in laboratory settings, may yield cortical activity bordering on that associated with alarm reactions. Similarly, Fentress (1992) and Caine (1992) argue that naive assumptions about the "neutrality" of human observers in ethological settings with canids and primates can compromise both research design and the interpretation of results. They argue that individuals in such settings rarely remain neutral and may be a potent source of behavioral variation often overlooked in seemingly unbiased field studies.

In short, human-based CRs come in a variety of forms. Whether appetitive or aversive, repeated experience with humans has the potential to modulate a range of dependent variables (Davis \& Balfour, 1992). Such uncontrolled effects may be most obvious in the case of behaviora research, yet their impact on biomedical and physiological studies is no less profound (e.g., Boccia, Broussard, Scanlan, \& Laudenslager, 1992). Indeed, Pavlovian conditioning of pituitary-adrenal, immune, and endorphin systems has already been documented (e.g., Ader, 1981; Maier, Laudenslager, \& Ryan, 1985).

Whereas human-based conditioning may confound experimental results, it may also facilitate interactions with animal subjects. Such techniques have been used to streamline a blood-sampling procedure (Reinhardt, 1992) and to maximize subject participation in cognitive testing with primates and birds (e.g., Boysen, 1992; Pepperberg, 1992). Regardless of whether the consequences are positive or negative, scientistanimal interactions will remain a factor in conducting animal research. Our demonstration that the ubiquitous laboratory rat can recognize familiar humans should, at the least, remind us that human-based conditioning can occur within a range of conventional research settings involving animal subjects.

\section{REFERENCES}

ADER, R. (ED.) (1981). Psychoneuroimmunology. New York: Academic Press.

BARNETT, S. A. (1963). A study in behaviour. London: Methuen.

Boccia, M., Broussard, C., Scanlan, J., \& Laudenslager, M. (1992). Practice makes predictable: The differential effect of repeated sampling on behavioral and physiological responses in monkeys. In H. Davis \& D. Balfour (Eds.), The inevitable bond: Examining scientist-animal interactions (pp. 153-170). New York: Cambridge University Press.

Boysen, S. T. (1992). Pongid pedagogy. In H. Davis \& D. Balfour (Eds.), The inevitable bond: Examining scientist-animal interactions (pp. 205-217). New York: Cambridge University Press.

CAINE, N. G. (1992). Humans as predators: Observational studies and the risk of pseudohabituation. In H. Davis \& D. Balfour (Eds.), The inevitable bond: Examining scientist-animal interactions (pp. 357. 364). New York: Cambridge University Press.
Calhoun, J. B., \& Handley, G. W. (1973). Long-term memory following serial discrimination reversal learning. Bulletin of the Psychonomic Society, 1, 354-456.

Davis, H., \& BALfoUR, D. (EDS.) (1992). The inevitable bond: Examining scientist-animal interactions. New York: Cambridge University Press

Davis H., \& Bradford, S. A. (1986). Counting behavior by rats in a simulated natural environment. Ethology, 73, 265-280.

Davis, H., \& Perusse, R. (1988). Human-based social interaction can reward a rat's behavior. Animal Learning \& Behavior, 16, 89-92.

Fell, L. R., \& ShUtT, D. A. (1989). Behavioural and hormonal responses to acute surgical stress in sheep. Applied Animal Behaviour Science, 22, 283-294.

FENTRESS, J. C. (1992). The covalent animal: On bonds and their boundaries in behavioral research. In H. Davis \& D. Balfour (Eds.), The inevitable bond: Examining scientist-animal interactions (pp. 44-71). New York: Cambridge University Press.

Gantt, W. H., Newton, E. O., Royer, F. L., \& Stephens, J. H. (1966). Effect of person. Conditional Reflex, I, 18-34.

HALPIN, Z. T. (1980). Individual odors and individual recognition: Review and commentary. Biology of Behavior, 5, 233-248.

HENDERSON, R. W. (1978). Forgetting of conditioned fear inhibition. Learning \& Motivation, 9, 16-30.

HopP, S. L., OWREN, M. J., \& MARION, J. R. (1985). Olfactory discrimination of individual littermates in rats (Rattus norvegicus). Journal of Comparative Psychology, 99, 248-251.

Maier, S. F., Laudenslager, M. L., \& RYan, S. M. (1985). Stressor controllability, immune function, and endogenous opiates. In F. R. Brush \& J. B. Overmeir (Eds.), Affect, conditioning, and cognition: Essays on the determinants of behavior (pp. 183-201). Hillsdale, NJ: Erlbaum.

MunN, N. L. (1950). Handbook of psychological research on the rat. Boston: Houghton Mifflin.

PePPERBERG, I. M. (1992). Social interaction as a condition for learning in avian species: A synthesis of the disciplines of ethology and psychology. In H. Davis \& D. Balfour (Eds.), The inevitable bond: Examining scientist-animal interactions (pp. 178-204). New York: Cambridge University Press.

RANDALL, J. (1989). Territorial-defense interactions with neighbors and strangers in banner-tailed kangaroo rats. Journal of Mammalogy, 70, 308-315.

REINHARDT, V. (1992). Improved handling of experimental rhesus monkeys. In H. Davis \& D. Balfour (Eds.), The inevitable bond: Examining scientist-animal interactions (pp. 171-177). New York: Cambridge University Press.

Settle, R. H., Sommerville, B. A., McCormick, J., \& Broom, D. M. (1994). Human scent matching using specially trained dogs. Animal Behaviour, 48, 1443-1448.

Slobodchikoff, C. N., Kiriazis, J., Fischer, C., \& Creef, E. (1991). Semantic information distinguishing individual predators in the alarm calls of Gunnison's prairie dogs. Animal Behaviour, 42, 713-719.

Steinert, P. A., Infurna, R. N., \& SPEAR, N. (1980). Long-term retention of a conditioned taste aversion in preweanling and adult rats. Animal Learning \& Behavior, 8, 375-381.

SummerleE, A. J. C. (1992). Behavioral arousal and its effect on the experimental animal and the experimenter. In H. Davis \& D. Balfour (Eds.), The inevitable bond: Examining scientist-animal interactions (pp. 132-152). New York: Cambridge University Press.

Tanida, H., Miura, A., Tanaka, T., \& Yoshimoto, T. (1995). Behavioral response to humans in individually handled weanling pigs. $A p$ plied Animal Behaviour Science, 42, 249-259.

THOR, D. H., \& Holloway, W. R. (1982). Social memory of the male laboratory rat. Journal of Comparative \& Physiological Psychology, 96, 1000-1006.

TimberlaKe, W., \& Grant, D. S. (1975). Auto-shaping in rats to the presentation of another rat predicting food. Science, 190, 690-692.

(Manuscript received June 3, 1996; revision accepted for publication October $9,1996$. 